\title{
ABORTO PROVOCADO: O DISCURSO DAS MULHERES SOBRE SUAS RELAÇÕES FAMILIARES ${ }^{1}$
}

\author{
Zannety Conceição Silva do Nascimento Souza², Normélia Maria Freire Diniz
}

\footnotetext{
${ }^{1}$ Recorte de dissertação - Aborto provocado no contexto da violência doméstica, apresentada ao Programa de Pós-graduação em Enfermagem da Universidade Federal da Bahia (UFBA), em 2009.

${ }^{2}$ Mestre em Enfermagem. Professora Auxiliar da Universidade Estadual de Feira de Santana. Bahia, Brasil. E-mail: zannety_ enfermeira@yahoo.com.br

${ }^{3}$ Doutora em Enfermagem. Professora Adjunto da UFBA. Bahia, Brasil. E-mail: nermelia@lognet.com.br
}

RESUMO: Aborto provocado e violência doméstica contra as mulheres são considerados problemas de saúde pública, pelas consequências à saúde física e mental que acometem as mesmas. Teve como objetivo analisar o discurso das mulheres que vivenciaram o aborto provocado sobre suas relações familiares. Os sujeitos da pesquisa foram 17 mulheres internadas em uma maternidade pública de Salvador, Bahia, Brasil, por aborto provocado. A coleta de dados aconteceu entre julho e setembro de 2008, através de entrevista semi-estruturada, organizada através do Discurso do Sujeito Coletivo. As ideias centrais que emergiram dos discursos mostram que a decisão de abortar derivou da história de violência vivenciada com companheiros e familiares, além do abandono quando a gravidez foi descoberta. A enfermagem necessita compreender o contexto social em que estão inseridas as mulheres que abortam, no sentido de reformular suas práticas.

DESCRITORES: Aborto. Violência. Enfermagem.

\section{INDUCED ABORTION: WOMEN'S SPEECH ON THEIR FAMILY RELATIONS}

\begin{abstract}
Induced Abortion and domestic violence against women are considered to be public health issues for the physical and mental health consequences they invoke. The objective of this study was to analyze the speech of women who experienced abortion concerning their family relationships. The subjects of the research were 17 women hospitalized in a public maternity in Salvador, Bahia, Brazil, for induced abortion. The data was collected between July and September 2008 through semi-structured interviews, organized from the Collective Speech of the Subject. The central ideas that emerged from their speeches show that the decision to abort was derived from the women's history of violence lived with their partners and relatives, besides the abandonment resulting from the discovery of their pregnancy. Nursing needs to understand the social context in which women who abort are inserted so that practices can be restructured.
\end{abstract}

DESCRIPTORS: Abortion. Violence. Nursery.

\section{EL ABORTO INDUCIDO: EL DISCURSO DE LAS MUJERES SOBRE SUS RELACIONES FAMILIARES}

RESUMEN: El aborto inducido y la violencia doméstica contra las mujeres se consideran problemas de salud pública por las consecuencias a la salud física y mental que afectan a las mismas. El objetivo fue analizar el discurso de las mujeres que han experimentado el aborto en sus relaciones familiares. Los sujetos del estudio fueron diecisiete mujeres ingresadas en una maternidad pública en Salvador, Bahia (Brasil), por causa del aborto inducido. La recolección de datos se realizó entre julio y septiembre de 2008, por medio de entrevistas semiestructuradas, organizadas a partir del Discurso del Sujeto Colectivo. Las ideas centrales que surgieron de los discursos muestran que la decisión del aborto se deriva de la historia de violencia vivida con sus compañeros y familiares, y del abandono cuando el embarazo fue descubierto. La Enfermería necesita entender el contexto social en el cual viven las mujeres que abortan, a fin de reformular sus prácticas.

DESCRIPTORES: Aborto. Violencia. Enfermería. 


\section{INTRODUÇÃO}

O aborto provocado e a violência doméstica são situações que incitam debates na sociedade contemporânea, pois envolvem percepções sobre dignidade, vida, ética, religião, valores morais, direitos das mulheres e gênero. Compreender gênero nestas duas situações inclui conhecer a trajetória da invisibilidade feminina ao longo da história e a maneira como se formaram as relações de subordinação homem/mulher na sociedade, bem como o controle dos corpos femininos e de suas funções sociais.

As histórias envolvendo aborto provocado e violências domésticas evidenciam a repressão de direitos femininos por parte do companheiro, família ou sociedade. Estas histórias revelam relatos de estupro dentro da própria relação conjugal, além de negligência financeira para com as mulheres, abandono e estigma social, o que acarreta agravos à saúde física e mental destas.

Considera-se aborto provocado o ato de interromper a gestação por motivo externo e intencional ${ }^{1}$ e a violência doméstica como qualquer ato violento cometido por pessoas que convivam no mesmo espaço doméstico, podendo ter ou não laços consaguíneos/vínculo parental e mesmo que esta convivência seja esporádica. ${ }^{2}$

Os agravos causados pelo aborto provocado e pela violência doméstica contra a mulher são motivos de muitos atendimentos nos serviços de saúde e a vulnerabilidade da mesma é notória, já que se observam consequências em várias instâncias que levam ao crescimento da morbimortalidade feminina.

Entre os problemas de saúde mencionados por mulheres decorrentes da violência conjugal estão: hipertensão, cefaléia, alterações de tireóide, afecções ginecológicas, gravidez indesejada, parto prematuro e aborto (seja ele espontâneo ou provocado), disfunção sexual, membros do corpo quebrados ou com lesões, inapetência, doenças sexualmente transmissíveis, insônia, depressão, ansiedade, baixa autoestima, um medo permanente, além de sentimentos de culpa, vergonha e humilhação. ${ }^{3-4}$ As consequências do aborto provocado no âmbito físico são hemorragias, infecções, lacerações uterinas, choque e em casos mais graves morte; no aspecto psicológico, a culpa, a vergonha e o estresse pós-traumático.

O adoecimento pelo aborto provocado e pela violência doméstica se tornou alvo de políticas públicas de saúde, já que as mulheres representam a maioria da população brasileira $(50,77 \%)$ e são as principais usuárias do SUS. ${ }^{5}$ O Ministério da Saúde (MS) aponta com base em estatísticas, que as complicações decorrentes de abortos inseguros são a quarta causa de morte materna no país. ${ }^{6}$ Vale ressaltar que em 2007, na cidade de Salvador, na Bahia, foi registrado em uma maternidade o maior número de internações devidas a aborto (1.713); o que corresponde a $20,6 \%$ das internações nos estabelecimentos públicos desta cidade. ${ }^{7}$

Não se trata, porém, de um número exato, uma vez que a maioria das mulheres opta pela clandestinidade do aborto por temer as punições legais e, nos serviços de saúde, se torna difícil identificar se todos os relatos de abortos espontâneos foram realmente verdadeiros, devido à dificuldade de uma relação de confiança entre a mulher e a equipe. Neste sentido, a curetagem é o segundo procedimento mais frequente na rede do SUS e em 2007 foram realizadas 8.387 curetagens. ${ }^{7}$ Além disso, as mortes maternas por hemorragia também podem ter sido fruto de abortos mal-sucedidos que não são incluídos nas estatísticas.

A respeito da violência doméstica, uma pesquisa recente assinalou que de cada 100 mulheres entrevistadas, 15 vivem ou já viveram algum tipo de violência doméstica, iniciada até os 19 anos de idade; contudo, apenas $40 \%$ destas denunciaram o agressor e em $87 \%$ dos casos os agressores são maridos e companheiros. ${ }^{8}$

Neste contexto, a mulher pode até conseguir sair da relação com o agressor, mas as suas lembranças permanecem causando estresse e trauma. Anos mais tarde, algum acontecimento sem importância pode fazê-la voltar ao passado e reviver suas ansiedades. Com isso, mantém-se a situação de vulnerabilidade. Ela permanece fechada em si mesma, persuadida de que o mundo exterior é hostil e pode permanecer por muito tempo se sentindo desvalorizada. ${ }^{9}$

Estudo recente mostra ainda que a violência doméstica e o aborto provocado fazem parte do cotidiano de muitas mulheres. ${ }^{10}$ No estudo, $88 \%$ das mulheres internadas por abortamento já haviam sofrido violência doméstica em algum momento de suas vidas, e 27,9\% destas associaram a decisão de abortar à violência doméstica sofrida. ${ }^{10}$

Considerando este contexto, o objetivo do estudo foi analisar o discurso das mulheres internadas em uma instituição de saúde da Bahia, que vivenciaram o aborto provocado, sobre suas relações familiares. 


\section{MÉTODO}

Trata-se de um estudo de abordagem qualitativa, pois consistiu numa busca pelo modo como a experiência social é criada e ressignificada. ${ }^{11}$ Foi realizado em uma maternidade da rede pública estadual da cidade de Salvador (Bahia), no período de julho a setembro de 2008, com 17 mulheres internadas por aborto provocado e histórico de violência doméstica. Para participar da pesquisa estas deveriam estar em boas condições clínicas e manifestarem o desejo através da assinatura do termo de consentimento livre e esclarecido. A pesquisa foi autorizada pelo Comitê de Ética em Pesquisa da Escola Estadual de Saúde Pública da Bahia, sob o parecer $n^{\circ} 242 / 2008$ e todo o processo respeitou a resolução do Conselho Nacional de Saúde $n^{\circ} 196$, de 10 de outubro de 1996, que trata da pesquisa com seres humanos.

Após a autorização do Comitê e o esclarecimento das participantes, a coleta de dados aconteceu através da entrevista semiestruturada, sendo utilizadas as seguintes perguntas para este estudo: "fale de sua relação com seu companheiro atual e/ou anteriores" e "fale um pouco da relação com sua família e/ou família do companheiro". Foi realizada com auxílio de gravador, e teve duração, em média, de uma hora, com transcrição subsequente na íntegra. Para aproximação com as mulheres, foram utilizados o acolhimento e a escuta desprovida de julgamentos. O contato com as participantes da pesquisa acontecia nas enfermarias, onde eram convidadas a conversar em um local mais reservado, ou ali mesmo, se assim o preferissem. Foi respeitado o sigilo através de nomes fictícios escolhidos pelas mesmas. O serviço de psicologia da instituição estava à disposição para assistir as participantes, se houvesse alguma intercorrência que exigisse o atendimento.

Os dados foram organizados e trabalhados através da estratégia metodológica discursiva do Discurso do Sujeito Coletivo (DSC). Esta indica que "o pensamento de uma coletividade sobre um dado tema pode ser visto como o conjunto dos discursos, ou formações discursivas, ou representações sociais existentes na sociedade e na cultura sobre esse tema, do qual, segundo a ciência social, os sujeitos lançam mão para se comunicar, interagir, pensar."12:16

Para a construção do DSC eram transcritas as entrevistas na íntegra, e procuravam-se nas falas individuais, pedaços, trechos ou transcrições literais do discurso, que eram sublinhadas, e que continham a essência do depoimento, do conteúdo discursivo, chamadas de Expressões-Chave (ECH). Nestas foram destacadas as Ideias Centrais (IC), que são nomes ou expressões linguísticas que revelam e descrevem da maneira mais sintética, precisa e fidedigna possível o sentido de cada um dos discursos analisados. As ideias centrais de mesmo sentido encontradas nos discursos individuais formaram uma ideia central síntese e esta abrigava o conjunto das expressões-chave referentes às mesmas. Estas expressões-chave eram organizadas em sequência, para posteriormente, constituírem o DSC. ${ }^{12}$ Cada passo foi inserido no Instrumento de Análise de Discurso (IAD1), composto por colunas, e contendo, respectivamente: expressões-chave, ideias centrais e ideia central síntese.

A partir daí, iniciou-se a construção do DSC com um novo Instrumento de Análise de Discurso (IAD2); a ideia central síntese continha o agrupamento de expressões-chave das ideias centrais que a formaram e, assim, duas colunas se formaram no IAD2. A primeira com estas expressões-chave agrupadas, e a segunda, o DSC que seria formado com as mesmas. Com a sequência dos trechos de expressões-chave, foram acrescentados conectivos para uni-las, obedecendo a uma coerência, com princípio, meio e fim do discurso. Neste processo de construção, é preciso discursivar, e partir do mais geral para o mais particular. Por fim, eliminaram-se as repetições de ideias, os particularismos dos discursos individuais, para a estruturação do Discurso do Sujeito Coletivo. ${ }^{12}$

\section{RESULTADOS E DISCUSSÃO}

No que tange ao contexto sóciodemográfi$\mathrm{Co}$, as participantes desta pesquisa foram em sua maioria adultas jovens, com ensino fundamental ou o segundo grau incompleto, autodeclaradas negras e pardas, desempregadas, solteiras, sustentadas por companheiro ou familiares; no aspecto reprodutivo, encontrou-se maioria de tercigestas ou multigestas, com história prévia de aborto provocado com uso do Cytotec $^{\circledR}$ (misoprostol).

\section{O discurso das mulheres sobre a relação com o companheiro}

As mulheres deste estudo relataram uma relação violenta com os companheiros atuais e algumas também com os anteriores, o que influenciou na decisão de abortar. Percebe-se na pesquisa que a afetividade dos companheiros se transfor- 
mou a partir da descoberta e desenvolvimento da gravidez; o comportamento destes mudou, pois a gravidez aumentou os conflitos nas relações conjugais. O conflito é parte estrutural das relações com os outros e, consequentemente, na vida em sociedade. ${ }^{13}$

Neste sentido, o desfecho dos conflitos foi a violência, pois estes não foram resolvidos pelo casal, para reestabelecer o respeito, a afetividade, as relações de proximidade, a confiança, ou seja, uma solução construtiva dos problemas. Isso pode ser evidenciado pelas ideias centrais síntese que serão analisadas em sequência.

A primeira ideia central síntese que será analisada e o DSC respectivo nos revelam um tipo de relação muito comum na atualidade brasileira que é o 'ficar'; este é desprovido de uma preocupação do homem e da mulher quanto ao corpo vinculado à reprodução. Outro aspecto é que as mulheres, em seus discursos expressam a busca de autonomia, no que se refere ao exercício da sexualidade, ou seja, as relações são motivadas pelo prazer.

\section{Ideia central síntese 1 - Amizade, festa, viajar juntos, vivíamos bem, até que engravidei}

A história com o pai do nenê foi assim: a gente era muito amigo, fazia muita festa junto, todo fim de semana a gente ia fazer churrasco, saía. Então, um desses dias eu dormi com ele de sábado para domingo, e domingo eu fui embora, ele para um lugar e eu para outro. [...] nossa relação? Ah, era mil maravilhas! [...] antes eu não queria porque eu já tinha saído de relacionamento há pouco tempo, não queria entrar de novo; só que ele, homem como é, palavras bonitas, não sei o quê, eu cai de novo e aí me enganei. A gente saiu, viajou e teve relacionamento, ai aconteceu: eu engravidei. Antes da gestação era muito frequente, carinhoso, hoje sumiu, mudou, não liga mais pra mim [...] (Discurso do sujeito coletivo 1, pergunta 2).

Assim, o discurso revela que a relação afetiva é frustrada quando a mulher descobre a gravidez e é abandonada pelo companheiro. $\mathrm{O}$ abandono denota a realidade do cotidiano das mulheres, ou seja, a gravidez se desenvolve no corpo feminino e a mulher fica responsável pela decisão de levar ou não a gravidez adiante.

Em outra perspectiva, os discursos das mulheres, a seguir, mostram que em determinadas situações, a decisão de abortar é da mulher, independe do desejo e/ou aceitação do companheiro, e que elas, mesmo diante da realidade do aborto inseguro, estão assumindo o direito em relação ao seu corpo e decidindo interromper a gestação, independente dos prejuízos que o ato possa lhe trazer.

\section{Ideia central síntese 2 - O companheiro brigou por ter usado remédio abortivo}

Ideia central sintese 3 - Ele disse que se tirasse o filho ia se separar de verdade; no dia que tomei o remédio, ele veio com ignorância, não sei se vou ficar com ele após o aborto

[...] agora porque eu tomei o remédio ele se retou e ficou falando. Ele já teve aqui e disse: menina você é maluca, rapaz, fica tomando remédio dos outros, não sabe nem o que é isso direito! Qualquer coisa que os outros te dá você faz, você lá sabe se ia funcionar ou não, pra você tomar, vocêpodia se prejudicar [...] (Discurso do sujeito coletivo 2, pergunta 2).

Ele disse se você tirar meu filho, a gente vai se separar de verdade. No dia que eu tomei o remédio, ele veio com ignorância, e eu fui mais grossa; ele disse que eu tinha perdido a fertilidade, ai eu falei que não me levasse mais não [na maternidade]; aí eu fui arranjar uma colega para me levar. [...] então eu não sei se ele vai querer ficar comigo ou se ele não vai [...] (Discurso do sujeito coletivo 3 , pergunta 3 ).

Os discursos acima apresentam a preocupação do companheiro com os efeitos maléficos da medicação abortiva para a saúde da mulher. Este conhecimento acerca das consequências do aborto inseguro se dá pela representação social existente, veiculada pela mídia, pela sociedade e pelos profissionais de saúde, de que o aborto clandestino é um ato perigoso, com risco para a vida.

Observa-se ainda, nos discursos, a divergência entre os parceiros, sobre a decisão de abortar; na prática cotidiana percebe-se que o acompanhamento e o cuidado da companheira no processo de abortamento são expressos de forma negligente. "O homem se isenta do compromisso, reproduz o discurso dos profissionais de saúde sobre risco e consequências do aborto inseguro que é veiculado pela mídia e por outros meios e não assume a responsabilidade juntamente com a mulher; com isso, se instala um conflito entre o casal, com o homem permanecendo em uma posição de observador: o fato de ter 'avisado' sobre os riscos o eximiria da participação na decisão da mulher de praticar o aborto e nos cuidados a ela." 14:61-2

Esta exclusão do homem, da responsabilidade no aborto provocado, é um aspecto do contexto feminino que precisa ser observado pelos profissionais no atendimento, já que o debate 
sobre a inserção masculina nas políticas de saúde reprodutiva é recente. A visão de gênero influi diretamente nas ações dos profissionais de saúde, pois estes mantém uma ênfase nos aspectos biológicos; e a mulher, na maioria das vezes, não tem chance de expressar seus conflitos conjugais e como estes influenciam no processo saúde-doença.

Em relação ao aborto provocado, o homem se distancia e apenas comparece à maternidade para buscar as mulheres no momento da alta. Por outro lado, existe uma cultura do silêncio, pois muitas vezes nem o companheiro, nem a família sabem ou participam do processo; muitas mulheres são admitidas nas maternidades sozinhas, para o atendimento às consequências do aborto provocado, não recebem visitas e nem companhia para a alta hospitalar.

A ideia central síntese 4 descreve que a decisão pelo aborto também é pautada na instabilidade financeira do companheiro.

\section{Ideia central sintese 4 - Relação com compa- nheiro não tem estabilidade}

Eu não me casei. Agora eu arrumei um companheiro, mas só que ele não era legal pra mim. É assim, não tem aquela estabilidade. Ele tem dois filhos só, e precisou a ex-mulher colocar ele na justiça; ai eu daqui, vendo isso tudo, já tendo visão de como ele era, futuro, se eu tivesse um filho com ele, como ia ser? Tentei evitar, tomava remédio, tudo, mas tomando remédio mesmo, engravidei dele. Agora ele tá aí, correndo atrás de trabalho, e disse que essa semana agora ia começar a trabalhar, e não começou a trabalhar; há muito tempo que ele vem procurando trabalho e não consegue (Discurso do sujeito coletivo 4, pergunta 2).

Para algumas mulheres, as relações conjugais, muitas vezes, vêm precedidas de um passado de paternidade não assumida pelo companheiro, e isso leva as mesmas a adotarem o papel de responsável pela família. Nesta construção familiar, o gênero permeia a divisão sexual do trabalho, e a mulher exige do companheiro o padrão tradicional "de homem". Em algumas sociedades, a definição do gênero feminino está tradicionalmente relacionada com a esfera familiar e a maternidade, enquanto que a referência fundamental para a construção social do gênero masculino é sua atividade na esfera pública, concentrando os valores materiais que fazem dele o provedor e protetor da família. ${ }^{15}$ Assim, a decisão da mulher em abortar também vislumbra não assumir o papel de provedora da família, diante de um companheiro que não cumpre esta "obrigação".
As ideias centrais síntese, que serão analisadas em seguida, apontam que a mulher vive a violência doméstica com seu parceiro, inclusive durante períodos de vulnerabilidade, como por exemplo, durante a gestação. A vivência de violência no âmbito doméstico é reflexo das relações de gênero. Como o espaço doméstico é, socialmente, considerado feminino, é lá onde as mulheres são as vítimas, na maioria das vezes, do agressor-companheiro.

Ideia central síntese 5 - A relação é péssima, já foi agredida duas vezes, de murro, empurrão, agressão verbal. Inclusive grávida, ficou com olho roxo. Deu queixa na delegacia das mulheres

[...] ele sempre me rejeita. Teve uma vez mesmo, nessa minha filha caçula, ele chegou pra mim, disse que não era filha dele, me esculhamba. Então, pra mim, tem sido difícil dá esta notícia [gravidez] pra ele, porque ele foi meu primeiro marido, meu devedor [primeiro parceiro sexual], vivo com ele há doze anos, e no primeiro filho ele não fez isso comigo não, mas da segunda pra cá ele me maltrata muito. Então é uma decisão que eu quero mesmo é estrangular [laqueadura tubária], porque eu tenho sofrido muito. Doze anos é muito, doze anos de sofrimento, e eu não quero mais essa vida pra mim [...] (Discurso do sujeito coletivo 5, pergunta 2).

Estudos ${ }^{16-17}$ reforçam este DSC, quando assinalam o aumento da violência conjugal no período gestacional manifestada de várias formas, sejam elas agressões físicas, patrimoniais e/ou psicológicas. A gravidez imprime uma parentalidade que altera o cotidiano do relacionamento afetivo do casal.

[...] péssima. Por isso mesmo que eu também não tive vontade de ter esse filho. Sabe, eu vim do interior, como eu já disse antes, e então eu não tenho ninguém de parente aqui, só tenho ele. Mesmo assim, tem vez que domingo ele trabalha até duas horas da tarde, e chega segunda, vai pro bar com os amigos, se divertir por ai, então eu sofro muito com ele. Uma vez mesmo eu tava grávida de minha filha, né? [...] aí eu passei no bar e pedi a ele um dinheiro pra comprar um leite; ele já tava meio embriagado e aí disse: pra que você quer dinheiro? Pra comprar o leite da menina; então ele começou a me xingar e eu xinguei ele também, aí ele pegou e me agrediu, no bar mesmo, na frente de todo mundo. Me deu um murro. Ainda fui dar uma queixa. Cheguei lá, não tinha levado os documentos, aí disseram: só amanhã, quando trouxer os documentos. No outro dia desisti de fazer a denúncia [...] (Discurso do sujeito coletivo 5 , pergunta 2). 
ODSC acima nos sinaliza a decisão de abortar, diretamente relacionada à violência doméstica conjugal. Esta, expressa em humilhação e dominação do homem em relação à mulher. "A relação entre homens e mulheres tem mostrado caráter de dominação, sendo designado para a mulher a condição de submissão, retratada em obediência, reprodução, fidelidade, cuidadora do lar e da educação dos filhos. Os papéis destinados à mulher foram ao longo dos anos naturalizando-se, apresentando as mesmas características, de tal modo que nascer, viver e morrer em situação de submissão tem se configurado de forma comum na maioria das sociedades." $4: 27$

$\mathrm{Na}$ atualidade, com a Lei Maria da Penha, ${ }^{18}$ as mulheres começaram a tomar conhecimento de seus direitos e do respaldo legal que possuem para a prevenção e o combate à violência doméstica. Mesmo assim, ainda é grande a falta de informação, e muitas mulheres ainda procuram a delegacia sem saber quais documentos são necessários para proceder à denúncia, e com isso, se perde a oportunidade de coibir muitos casos de agressões, já que a volta ao ambiente doméstico aumenta as chances da mulher desistir, quer pela presença dos filhos, quer pela perda de coragem mesmo.

\section{O discurso das mulheres sobre a relação com família}

As ideias centrais sínteses e discursos que serão analisados nesta etapa retratam que relações complexas e violentas com outros familiares, repercutem também na decisão de muitas mulheres pelo aborto provocado.

Foi evidenciado neste estudo que a violência doméstica gera um distanciamento relacional entre mãe e filha; o DSC 6 relata o abandono vivenciado desde a infância, a negligência da mãe com relação ao processo de desenvolvimento da filha e a falta de uma relação amorosa. É a partir da relação da menina com ela mesma, com a sua mãe, e a mãe de sua mãe, que seu 'ser mulher' será construído, por meio de um processo de invenção e criação da feminilidade. ${ }^{19}$

\section{Ideia central sintese 6 - Mãe privava de muita coisa quando criança, sempre gostou mais de filho homem, hoje a trata com ignorância, e isso pesou na decisão de abortar}

Eu não sei dizer como era a relação com minha mãe. Desde criança ela me priva de muita coisa, não deixava usar short [...] ela disse que se pudesse tinha os filhos todos homens [...]. Ela não deixa eu almoçar direito, me nega comida, me nega tudo. Antes de sair pra ela trabaiar [...] tranca tudo dentro do quarto pra eu não comer. Aí já pensou: eu com filho, com filho ia ser pior ainda, não ia dá nada, não ia ajudar, ia querer que eu passasse fome, eu ia passar fome [...]. E eu disse: - é a senhora, já abortou tanto, e ela não diz nada, ela fica calada [...]. Porque quando a gente era menor, na hora que ela ficava bêbada, a gente fazia o que queria, deixava a gente ir pra rua, agora não! Agora que ela parou de beber e prende muito. O meu coração para ela está bem fechado, não sei se eu chegar em casa hoje ou amanhã se eu vou falar com ela normal, pra mim tanto faz como tanto fez. Quem me criou foi minha vó; minha vó me dá mais carinho, mas minha mãe não, minha mãe é mais ignorante. Ela xinga, bate, me esculhamba [...]. Atéhoje ela não me considera como filha não. Pra ela é como se eu não fosse nada entendeu? [...]. De certa forma pesou [na decisão de abortar], porque eu não tive o carinho de mãe, [...] sempre fui muito carente de mãe. Nunca tive apoio. Quando fiquei moça pela primeira vez, tive que contar a meu pai [...] quando dei meu primeiro beijo, quando eu tive meu primeiro namorado, sempre quis contar tudo pra minha mãe. Só que não podia porque ela nunca tava comigo, sempre tava distante; [...] aí eu fico assim, pensando assim: por quê será que minha mãe me trata dessa forma, o que será que eu fiz a ela? Será que no momento que ela me teve, ela não me desejou? Da mesma forma que eu não desejei o meu agora? Aí eu acho que se minha mãe tivesse assim totalmente sempre comigo isso não teria acontecido, ou se tivesse acontecido, eu não teria abortado, entendeu? [...] (Discurso do sujeito coletivo 6, pergunta 4).

Isso remete mais uma vez ao debate sobre a formação da personalidade feminina; em decorrência das relações construídas com a mãe na infância e na adolescência, percebemos que o DSC acima aponta uma carência expressa pelo desejo de ter compartilhado com a mãe as experiências de sua juventude nos dois principais marcos da sexualidade da adolescente: a primeira menstruação e o primeiro beijo.

Em diferentes culturas, a menstruação tem sua importância: é o sinal biológico de que a mulher está preparada para a reprodução da espécie, principalmente porque a sua ausência, em mulheres com ciclo menstrual regular, denota uma provável gravidez. ${ }^{20}$ Cada mulher vivencia esta passagem da infância para a puberdade de forma diferente e traz com ela crenças, tabus e significados, geralmente compartilhados com outras mulheres, principalmente com as mães.

Ainda em relação à família, o modelo tradicional de pai é pautado em imagens do pai rígido, 
distante, investido de autoridade, mais comprometido com a disciplina, a norma e a punição, do que com a relação afetiva pai-filho. ${ }^{21}$ Os discursos das mulheres deste estudo, expresso na ideia central síntese 7, mostram o desenvolvimento de uma identidade a partir da convivência em lares onde a violência permeava as relações entre os pais, e destes com os filhos.

\section{Ideia central síntese 7 - Pai é sempre ofensivo, bebe e xinga, todo mundo tem medo dele por isso faz aborto escondido}

[...] com meu pai é horrível [...]. Meu pai é muito crítico, tudo ele critica, ele ofende a pessoa que nem sente. Ele é brabo mesmo, qualquer coisinha ele gosta de bater, essas coisas, mas hoje ele não me bate mais; ele bebe, fica esculhambando, não vou mentir. Aí eu digo: - pô, imagine se eu tiver grávida, o que é que ele vai falar de mim, o que é que ele vai falar às pessoas, fiquei pensando assim, por isso que minha mente ficou muito perturbada e eu fiz as coisas sem pensar direito [...]. Aí pronto, todo mundo tem medo dele, de pai. Ele não gosta que eu faço aborto, ele diz: se engravidar dez vezes, dez vezes é pra parir. Aí eu faço escondido dele. Só que ele é um tipo de pai bem antigo, ele acha que eu tenho que dormir cedo, então tem vezes que ele fala as coisas, eu não concordo e debato com ele. Aí ele disse que eu sou muito ousada [...] (Discurso do sujeito coletivo 7 , pergunta 4 ).

Mesmo com a modernidade e a evolução dos hábitos e costumes da família, encontramos muitos relatos de violência doméstica contra a mulher, cometida pela figura paterna. Se o pai se utiliza da violência para um exercício do poder no lar é porque não existe mais a predominância deste pátrio poder nas relações atuais. Assim sendo, a figura do pai, que tinha como papel orientar os filhos, estabelecendo as regras e os limites domésticos, diante de uma juventude que cresceu sem a presença afetiva e efetiva de um pai, vem desaparecendo; os filhos não reconhecem mais sua autoridade.

O trecho do discurso 8 demonstra que a mulher que aborta o faz, em alguns casos, em um contexto de desestruturação familiar.

\section{Ideia central síntese 8 - Não tem pai, nem mãe, os irmãos são desunidos, a única parente próxima é uma tia}

[...] meu pai faleceu, eu não conheço não. Desde que eu nasci que eu não conheço meu pai não. Num é uma família assim unida [volta a chorar] cada um vive sua vida. Minha mãe era muito boa [permanece chorando], se eu ainda tivesse minha mãe, não passava metade dessas coisas. Ninguém sabe pra onde eu fui. Sabe que eu vim pra um hospital, mas não sabe pra onde eu fui. Meus irmãos são muito desunidos, um não liga para ou tro não. E aí eu só tenho mesmo Deus, meus filhos, e às vezes ele né, meu esposo [...]. Agora, as únicas pessoas próxima a mim, é minha tia, só ela que fala comigo, me apóia em tudo. É a única parente que eu tenho, que me apóia em tudo, é minha tia [...] (Discurso do sujeito coletivo 8, pergunta 4).

Percebe-se neste discurso uma ausência de cuidado familiar nos momentos em que a mulher estava mais vulnerável, tendo provocado o aborto. "A família se inclui entre as instituições sociais básicas..., é apontada como elemento-chave não apenas para a 'sobrevivência' dos indivíduos, mas também para a proteção e a socialização de seus componentes, transmissão do capital cultural, do capital econômico e da propriedade do grupo, bem como das relações de gênero e de solidariedade entre gerações". 22:109

Ainda no que se referem às relações familiares, muitas vezes estas são fonte de apoio e resiliência para as mulheres que provocam o aborto, quando as relações conjugais são desequilibradas. Neste sentido, o discurso 9 mostra que parte das mulheres do estudo recebe apoio emocional dos familiares, mesmo assim efetivam o aborto de forma silenciosa.

\section{Ideia central sintese 9 - $O$ relacionamento familiar é bom, ama os parentes porque o marido não vale nada}

Pra mainha tá difícil, por ser mãe, por ser evangélica e tudo, ela não concordou. Mas ela não sabia, eu tomei [medicação abortiva] escondido em casa. Eu sei que eu fiz uma coisa perigosa, porque escondido, se eu tivesse uma reação, não ia ter ninguém pra me ajudar, que eu moro sozinha. Aí eu contei com ela, mas ela me deu apoio, porque mãe é mãe, né? [...] Meu pai é maravilhoso [...]. Somos unidos, com minha família é maravilhoso, meus pais são tão queridos, meus irmãos [...] eu amo meus parentes demais, é a esperança, é tudo que eu tenho, eles e meus filhos, porque o resto, marido não vale nada! (Discurso do sujeito coletivo 9, pergunta 4 )

Observa-se neste discurso que a mulher tem o acolhimento da mãe, mesmo sendo a genitora de uma religião que condena algumas atitudes como o aborto; porém, independente do acolhimento, as 
mulheres relatam o aborto provocado de forma solitária ${ }^{10}$ e perigosa. Os companheiros e outros familiares tomam conhecimento da situação, geralmente após a utilização da substância abortiva ou quando se encontra a mulher na unidade hospitalar em atendimento de emergência, por ocasião da curetagem.

Isso acontece porque a mulher possui o sentimento de vergonha depois que provoca o aborto, pois encarar a família é se deparar com os valores sociais que envolvem o aborto provocado como a ilicitude. Esta vergonha é descrita no DSC referente à ideia central síntese 10 .

\section{Ideia central sintese 10 - A cabeça fica perturbada com a gravidez porque não curtiu a vida de casado; se sente aliviada após aborto, mas tem vergonha de encarar a família}

A cabeça fica perturbada demais, fica pensando mil coisa, a gente nem casou ainda, nem curtiu a vida de casado, pra filho entrar agora e tal. A gente nem construiu nossa casa direito [...] a gente fica perturbada. Agora [após aborto] eu me sinto bem melhor, agora eu me sinto mais aliviada, porque eu tava assim num sufoco, com medo, nervosa, agora graças a Deus já passou, tudo. Agora é a vergonha, muita vergonha de encarar minha família, muita mesmo. Eu não tenho cara pra chegar em casa, não tenho, a vergonha é tão grande! Mas vou ter que ir, não tem jeito mesmo, não tem pra onde correr né? (Discurso do sujeito coletivo 10, pergunta 4 ).

Em alguns casos, a sensação da mulher depois do aborto é de alívio, mas também vergonha, porque socialmente o aborto é um ato que fere a moral. "Moral é definida como um conjunto de regras restritivas da liberdade individual, de caráter obrigatório, cuja finalidade é garantir harmonia do convívio social" .23:16

Na situação do aborto provocado, a vergonha vem associada à exposição e o juízo. A mulher que aborta faz um juízo de si mesma com base nos consensos sociais existentes; porém, mais do que isso, pensa em como será julgada pelas demais pessoas daquele contexto, pela equipe de saúde que lhe presta assistência, até pela família quando de seu retorno a casa. Quanto a se expor, sua preocupação reside no fato de ter provocado o aborto numa sociedade para a qual esta situação é considerada crime, ter que assumir diante do serviço de saúde e da comunidade sua atitude. A vergonha decorre do fato de que quando estamos expostos, há uma assimetria na relação de poder: quem está observando é sujeito na ação e quem está sendo observado é o objeto, de onde a vulnerabilidade do sujeito-objeto. ${ }^{23}$

Tal vulnerabilidade, na mulher, se dá ainda pelas questões do gênero e pelo estigma do aborto que a acompanha: "a sociedade estabelece os meios de categorizar as pessoas e o total de atributos considerados como comuns e naturais para os membros de cada uma dessas categorias". ${ }^{24: 11}$ O termo estigma é algo profundamente depreciativo e o aborto se insere no estigma das culpas individuais: aí a mulher se vê enquanto criminosa e assassina do seu filho. ${ }^{24}$

\section{CONSIDERAÇÕES FINAIS}

$\mathrm{O}$ estudo mostrou que as mulheres que vivenciaram aborto provocado convivem em relações familiares conflituosas, não trabalhadas e expressas pela ausência da busca pelo acordo para resolução construtiva dos problemas. Essa situação acaba gerando violência doméstica, manifestada de várias formas, tais como: abandono, privação de liberdade, manipulação afetiva e lesões corporais.

Assim, no que se refere à convivência, as mudanças de relações afetivas por parte do companheiro aconteceram com a descoberta da gravidez, dando espaço para atos violentos, levando às mulheres a decidirem pelo aborto. A pesquisa assinalou o aumento da violência por parte do companheiro, no período da gestação. Vale ressaltar que o abortamento provocado é vivido de forma solitária pelas mulheres, já que o homem está presente em alguns casos, apenas na alta hospitalar pós-curetagem.

Em relação à família de origem, os discursos apontam vivência da violência doméstica desde a infância e relacionam a ausência do apoio familiar à decisão de abortar.

Cabe à enfermagem, considerada profissão do cuidado, proporcionar às mulheres em abortamento provocado, um atendimento sem julgamentos, nem punições verbais ou físicas, partindo da escuta afetiva para a resolução das demandas advindas das mesmas. Assim, uma estratégia é acolher as mulheres, favorecendo o vínculo de confiança, para que as mesmas possam quebrar a lei do silêncio e falar de suas experiências. Para que isso aconteça, é mister que as(os) enfermeiras(os) e sua equipe se desvencilhem de estereótipos presentes em nossa cultura, no que diz respeito ao aborto e à violência. 


\section{REFERÊNCIAS}

1. Faúndes A, Barzelatto J. O drama do aborto: em busca de um consenso. Campinas (SP): Komedi; 2004.

2. Ministério da Saúde (BR). Secretaria de Atenção à Saúde. Departamento de Ações Programáticas Estratégicas. Manual violência intrafamiliar: orientações para a prática em serviço. Cadernos de Atenção Básica $n^{\circ} 8$; série $A$ - Normas e manuais técnicos - no 131. Brasília (DF): MS; 2002.

3. Souza VLC. A violência conjugal e sua influência na decisão da mulher pelo aborto [dissertação]. Salvador (BA): Universidade Federal da Bahia. Programa de Pós- Graduação em Enfermagem; 2000.

4. Monteiro CFS, Souza IEO. Vivência da violência conjugal: fatos do cotidiano. Texto Contexto Enferm. [online]. 2007 [acesso 2010 Jun 03]; 16(1):26-31. Disponível em: http://www.scielo. br/scielo.php?script=sci_arttext\&pid=S010407072007000100003\&lng=pt

5. Ministério da Saúde(BR). Secretaria de Atenção à Saúde. Departamento de Ações Programáticas Estratégicas. Política nacional de atenção integral à saúde da mulher: princípios e diretrizes. Brasília (DF): MS; 2007.

6. Ministério da Saúde (BR). Portal da Saúde (SUS). Aborto inseguro: um problema de saúde pública. Norma técnica humaniza atendimento às mulheres com complicações de abortamento. 2011 [acesso 2011 Set 07]. Disponível em: http:/ / portal.saude.gov.br/ saude/visualizar_texto.cfm?idtxt $=22411$

7. Simonetti C, Souza L, Araújo MJO. Dossiê a realidade do aborto inseguro na Bahia: a ilegalidade da prática e seus efeitos na saúde das mulheres em Salvador e Feira de Santana. Dez. Salvador (BA): [material impresso]; 2008.

8. Senado Federal (BR). Secretaria de Pesquisa e Opinião Pública. Relatório Analítico: Pesquisa de Opinião Pública Nacional: Pesquisa sobre Violência Doméstica contra a Mulher. Datasenado. 2007. [acesso 2011 Ago 31]. Disponível em: http:/ / www. senado.gov.br/noticias/datasenado/pdf/ Relatório analítico Violência Doméstica.pdf

9. Hirigoyen MF. A violência no casal: da coação psicológica à agressão física. Tradução de Maria Helena Kuhner. Rio de Janeiro (RJ): Bertrand Brasil; 2006.

10. Pérez BG. Aborto provocado: representações sociais de mulheres [dissertação]. Salvador (BA): Universidade Federal da Bahia. Programa de PósGraduação em Enfermagem; 2006.

11. Denzin NK, Lincoln, YS. O planejamento da pesquisa qualitativa: teorias e abordagens. $2^{\mathrm{a}} \mathrm{ed}$. Porto Alegre (RS): Artmed; 2006.
12. Lefévre F, Lefevre AMC. O discurso do sujeito coletivo: um novo enfoque em pesquisa qualitativa. $2^{\mathrm{a}}$ ed. Caxias do Sul (RS): Educs; 2005.

13. Muller, JM. Não-violência na educação. São Paulo (SP): Palas Athena; 2006.

14. Souza, ZCSN. Aborto provocado no contexto da violência doméstica: o discurso das mulheres [dissertação] Salvador (BA), Universidade Federal da Bahia. Programa de Pós-graduação em Enfermagem; 2009.

15. Giffin K. Violência de gênero, sexualidade e saúde. Cad Saúde Pública. 1994 Jan; 10(1):146-55.

16. Menezes TC, Amorim MMR, Santos LC, Faúndes A. Violência física doméstica e gestação: resultados de um inquérito no puerpério. Rev. Bras. Gincecol. Obstet. 2003 Jun, 25(5):309-16.

17. Couto TM. Mulher, gestação e violência: da dimensão factual à existencial [dissertação]. Salvador (BA): Universidade Federal da Bahia; 2003.

18. Brasil. Presidência da República. Lei n ${ }^{\circ} 11.340$, de 7 de agosto de 2006: cria mecanismos para coibir a violência doméstica e familiar contra a mulher e dispõe sobre a criação dos Juizados de violência doméstica e familiar contra a mulher; altera o Código de Processo Penal, o Código Penal e a Lei de Execução Penal; e dá outras providências. Poder Executivo, Brasília: 2006 [acesso 2008 Jan 10]. Disponível em: http:/ / www.planalto.gov.br/ Ccivil_03/_Ato2004-2006/2006/Lei/L11340.htm

19. Rinaldi D. Mistérios da feminilidade: a relação mãe e filha no difícil caminho do "tornar-se mulher" [resenha]. Estud Pesqu Psicolo [online]. 2003 [acesso 2009 Mar 25]; 3(2):1-4. Disponível em: http:/ / www. revispsi.uerj.br/v3n2/artigos/resenha.html

20. Sardenberg CMB. Estudos feministas: um esboço crítico. In: Amaral CCG, organizador. Teoria e práxis dos enfoques de gênero. Salvador (BA): REDORNEGIF; 2004. p. 17-40.

21. Nolasco SA. O mito da masculinidade. Rio de Janeiro (RJ): Rocco; 1993.

22. Carvalho IMM, Almeida PH. Família e proteção social. São Paulo Perspec [online]. 2003 [acesso 2008 Jan 10]; 17(2):109-22. Disponível em: http:/ / www. scielo.br/scielo.php?script=sci_arttext\&pid=S0102$88392003000200012 \& \operatorname{lng}=$ pt\&nrm=iso

23. La Taille Y. Vergonha: a ferida moral. $2^{\text {a }}$ ed. Rio de janeiro (RJ): Vozes; 2002.

24. Goffman E. Estigma: notas sobre a manipulação da identidade deteriorada. $4^{\mathrm{a}}$ ed. Rio de Janeiro (RJ): LTC; 1988. 